\title{
Inovação e os efeitos sobre a dinâmica de mercado: uma síntese teórica de Smith e Schumpeter
}

\author{
Innovation and the effects on market dynamics: a theoretical synthesis of \\ Smith and Schumpeter
}

\section{Innovation et effets sur la dynamique du marché: une synthèse théorique et Smith Schumpeter}

\author{
Innovación y efectos sobre la dinámica del mercado: una síntesis teórica y \\ Smith Schumpeter
}

\author{
Matheus Silva de Paiva ${ }^{1}$ \\ George Henrique de Moura Cunha ${ }^{1}$ \\ Celso Vila Nova Souza Junior ${ }^{1}$ \\ Michel Constantino ${ }^{2}$
}

Recebido em 05/04/2017; revisado e aprovado em 10/05/2017; aceito em 19/05/2017

DOI: http://dx.doi.org/10.20435/inter.v19i1.1561

\begin{abstract}
Resumo: O presente artigo tem por objetivo realizar uma resenha dos conceitos de relativos à inovação e a empresário, bem como investigar como produzem efeitos sobre o capitalismo, em Adam Smith e Schumpeter. Logo, parte-se de Adam Smith, com seus conceitos de "capitalista" e "divisão do trabalho", comparando-os com "inovação" e "empreendedor" de Joseph Schumpeter. Este trabalho é significativo, porquanto a inovação é a chave para se compreender a evolução do sistema capitalista e, portanto, ajuda a compreender os efeitos de políticas públicas de inovação no sistema capitalista brasileiro.
\end{abstract}

Palavras-chave: inovação; capitalismo; teoria econômica.

Abstract: The purpose of this article is to review the concepts of innovation and entrepreneurship as well as to investigate how they produce effects on capitalism in Adam Smith and Schumpeter. It then begins with Adam Smith, with his concepts of "capitalist" and "division of labor", comparing them with "innovation" and "entrepreneur" by Joseph Schumpeter. This work is significant, since innovation is the key to understanding the evolution of the capitalist system and, therefore, helps to understand the effects of public policies of innovation in the Brazilian capitalist system.

Keywords: innovation; capitalism; economic theory.

Résumé: Le but de cet article est d'examiner les concepts d'innovation et d'entrepreneuriat ainsi que d'étudier comment ils produisent des effets sur le capitalisme chez Adam Smith et Schumpeter. II commence alors par Adam Smith, avec ses concepts de «capitaliste» et de «division du travail», en les comparant à «innovation» et «entrepreneur» de Joseph Schumpeter. Ce travail est important car l'innovation est la clé de la compréhension de l'évolution du système capitaliste et, par conséquent, permet de comprendre les effets des politiques publiques d'innovation dans le système capitaliste brésilien.

Mots-clés: innovation ; capitalisme ; theorie économique.

Resumen: El propósito de este artículo es revisar los conceptos de innovación y emprendimiento, así como investigar cómo producen efectos sobre el capitalismo en Adam Smith y Schumpeter. Luego comienza con Adam Smith, con sus conceptos de "capitalista" y "división del trabajo", comparándolos con "innovación" y "empresario" de Joseph Schumpeter. Este trabajo es significativo, ya que la innovación es la clave para entender la evolución del sistema capitalista y, por tanto, ayuda a comprender los efectos de las políticas públicas de innovación en el sistema capitalista brasileño.

Palabras clave: innovación; capitalismo; teoría económica.

\footnotetext{
${ }^{1}$ Universidade Católica de Brasília (UCB), Brasília, Distrito Federal, Brasil.

2 Universidade Católica Dom Bosco (UCDB), Campo Grande, Mato Grosso do Sul. Brasil.
} 


\section{INTRODUÇÃO}

O conceito de "inovação" é amplamente utilizado em Economia. Sua definição mais simples, contida em qualquer dicionário ordinário, consiste no processo de transformar uma ideia ou invenção num bem ou serviço (INNOVATION, s.d.). Essa definição, ainda que correta, não contempla toda a dimensão que ela possui em Economia, como será visto adiante. Igualmente importante para a compreensão da rotina empresarial e do desenvolvimento econômico, o conceito de "empreendedor" durante muito tempo foi negligenciado pela teoria econômica. Durante muitos anos, ambos os conceitos foram relegados a uma posição secundária dentro da teoria, o que impediu a compreensão adequada do funcionamento do capitalismo e do complexo processo de tomada de decisão empresarial.

Nessa esteira, o presente artigo pretende retomar os conceitos de "inovação" e de "empreendedor" na obra de Adam Smith e Schumpeter. Além disso, pretende-se mostrar como são úteis para explicar a dinâmica econômica de sociedades capitalistas e, em particular, serão usados para esclarecer a situação de recessão econômica em que se encontra a economia brasileira, bem como para compor políticas públicas para sua recuperação econômica.

\section{UM PANORAMA GERAL SOBRE A INOVAÇÃO E A DINÂMICA CAPITALISTA}

O termo "inovação" se popularizou em Economia através do economista Joseph Schumpeter em seu livro "Teoria do Desenvolvimento Econômico" publicado em 1912. Para esse autor, o termo "inovação" não se reduz pura e simplesmente àquilo que é novo ou a alguma novidade vendável. Muito mais do que isto, a "inovação" é o principal mecanismo pelo qual o capitalismo se desenvolve. De forma paralela, o termo "empreendedor", igualmente importante para entender o funcionamento do capitalismo e amplamente relacionado com o termo "inovação", apareceu originalmente em Cantillon, cerca de vinte anos antes de Adam Smith, referindo-se ao indivíduo capaz de observar e aproveitar as discrepâncias entre a oferta e a demanda no mercado para lucrar (BLAUG, 1995, p. 460).

Para Cantillon, o empresário é um indivíduo especialista em assumir riscos. Para ele, ao empregar os trabalhadores, o empresário estaria, de fato, proporcionando-Ihes proteção econômica, isto é, garantindo o salário para os trabalhadores sem saber, com certeza, se os frutos do trabalho dos empregados encontrarão demanda suficiente para compensar a contratação. Nesse sentido, os trabalhadores recebem um salário certo enquanto que o empresário assume os riscos das possíveis mudanças no preço e na quantidade demanda da mercadoria no futuro (PEÑALOZA, 2016).

Segundo Schumpeter (apud MCCRAW, 2012), o empreendedorismo é uma ferramenta essencial na sociedade por onde se utiliza a agregação de valor e a identificação de oportunidades de negócios para se satisfazer uma demanda potencial e auferir um diferencial de lucro. A palavra empreendedorismo (entrepreneur) tem origem francesa e quer dizer aquele que assume riscos e começa algo novo (HISRICH; PETERS, 2004).

Nesse sentido, a "inovação", atividade basilar do empreendedor, é engendrada quando esse empresário inovador percebe que pode produzir um produto ou serviço por meio de novos arranjos produtivos e, portanto, conquistar uma oportunidade de lucro acima da média dos mercados - a diferença dos lucros é chamada de "lucro do empresário schumpeteriano" (PEÑALOZA, 2016). Ele então age de forma a aproveitar essa oportunidade de negócio, criando coisa nova, 
o que induz à alteração na natureza da demanda - preferências dos consumidores - o que, portanto, impulsiona as flutuações na produção. Essa reestruturação na demanda agregada se deve, sobretudo, à destruição criativa realizada pelo empreendedor, ou seja, com a "inovação" destroem-se hábitos de consumo e investimento antigos e criam-se novos.

Nessa perspectiva, ao desenvolver, por exemplo, um novo aparelho que melhore a comunicação interpessoal, o empreendedor estimula o uso desse novo dispositivo em detrimento do antigo, substituindo-o paulatinamente. Nessa esteira, a ruptura no equilíbrio econômico provoca reavaliações de consumo e de investimento e, portanto, promove a revisão das decisões microeconômicas. Uma vez incorporadas estas novas informações provenientes da "inovação", e refeitas estas decisões, os impactos da "inovação" são diluídos dentro do sistema capitalista, possibilitando a recuperação da estabilidade econômica, todavia num patamar de desenvolvimento superior (ŚLEDZIK, 2013, p. 90).

Schumpeter interpreta o capitalismo de uma maneira muito especial e inovadora, atribuindo ao empresário inovador (empreendedor) um papel central na dinâmica capitalista. Para ele, empreender significa a "criação de novas combinações", e a figura do empreendedor está conectada à ideia de quem irá implementar essas novas combinações. Esse empreendedor, por sua vez, vive num mundo incerto, e ainda sim é dotado de coragem para iniciar novos empreendimentos e lutar contra a segurança da zona de conforto (HEERTJE, 2008, p. 321).

Em seu livro "Socialismo, Capitalismo e Democracia", Schumpeter explica o funcionamento real do sistema capitalista, afastando os mitos que existem sobre a concorrência perfeita, a competição via preços e o rendimento do produto máximo. Por concorrência perfeita entende-se a estrutura de mercado cujo preço do produto/serviço é dado, isto é, onde as firmas e os consumidores são tão numerosos que são incapazes de influenciá-lo. Conectada à ideia de estrutura de mercado, está a ideia de competição via preços. Esse conceito refere-se à capacidade de a firma escolher um preço que esteja acima do seu custo marginal ${ }^{3}$ sem que, para isso, tenha de perder todo o mercado - como aconteceria sob competição perfeita. Esse conceito refere-se, também, ao grau de concentração do mercado e ao grau de diferenciação do produto/serviço. Assim, quanto menos empresas estiverem operando num mesmo mercado, menor será a oferta deste bem, maior será o poder de mercado das empresas instaladas e, portanto, maior tenderá a ser o preço de mercado em relação ao custo marginal dessas empresas. De maneira semelhante, quanto maior for o teor de diferenciação de um bem, menor a quantidade de empresas capaz de produzir este bem e, portanto, menor o número de empresas concorrentes. Isto, por sua vez, acarreta uma menor oferta e, logo, um preço de equilíbrio de mercado maior que o custo marginal. Em outras palavras, a competição via preço é o mecanismo de alocação dos mercados: quando há um excesso de oferta, o preço se reduz para evitar o desperdício e, quando há um excesso de demanda, o preço se eleva para que arbitrariedades sejam feitas para alocar os recursos (MANKIW, 2015, p. 66).

Em contraposição, em seu livro "Socialismo, Capitalismo e Democracia", Schumpeter (1961, p.108) argumenta que a estrutura de mercado no capitalismo jamais foi a de concorrência perfeita, nem mesmo em sua origem; tampouco o principal mecanismo de competição foi realizado via preços. O autor refuta este modelo de explicação do desenvolvimento do capitalismo porque se trata, sobretudo, de um conceito estático e rígido, enquanto que o capitalismo histórico foi um

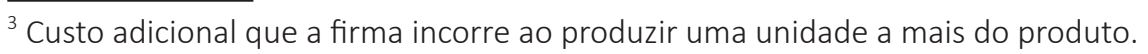


processo em evolução, nunca alterado, dinâmico, que transforma a sociedade e é transformado por ela. Nesse sentido, atesta o autor, "o problema usualmente estudado é o da maneira como o capitalismo administra a estrutura existente, ao passo que o problema crucial é saber como ele as cria e destrói" (SCHUMPETER, 1961, p. 111).

Como bem mencionado por Schumpeter (1961, p. 112), a concorrência que se observa no seio da economia capitalista é a de novos bens, novas tecnologias, novas fontes de insumos, novos modos de as firmas se organizarem. Nessa esteira, ainda que importantes, os preços possuem um papel secundário na determinação do nível de concorrência dos mercados. Note como todas as formas de concorrência apontadas pelo autor trazem em si a noção de "novo" ou "novidade" ou, mais precisamente, de "inovação". Essa constatação não é coincidência, uma vez que foi Schumpeter quem atribuiu um papel fulcral para a inovação para o entendimento adequado do funcionamento do sistema capitalista.

Posto isto, o presente artigo tem por objetivo resgatar o conceito de "inovação" e "empreendedor" em Economia, bem como acompanhar seu desenvolvimento desde a concepção de Adam Smith até a literatura neo-schumpeteriana. Além disso, pretende-se analisar o papel do empreendedor e como suas inovações afetam a trajetória do sistema capitalista e o nível de bem-estar social. Para tanto, parte-se da noção de divisão de trabalho em Smith, passando pela conceituação fornecida por Schumpeter e, posteriormente, recorre-se à literatura que se consolidou como "Economia da Inovação" para buscar o fio condutor do conceito ao longo do século passado e começo do século XXI.

\section{ADAM SMITH E A DIVISÃO DO TRABALHO: O GÉRMEN TEÓRICO SOBRE O FUNCIONAMENTO DO CAPITALISMO}

No início de seu livro "A Riqueza das Nações", publicado pela primeira vez em 1776, Adam Smith não deixa dúvidas de que está lidando com o tema "desenvolvimento econômico", isto é, com as forças de longo prazo que governam o crescimento e, portanto, a riqueza das nações (BLAUG, 1995, p. 36).

Um primeiro mecanismo central no entendimento da dinâmica capitalista surge sob o nome de "divisão do trabalho", o qual seria capaz de aumentar a riqueza da nação ao repartir as etapas de produção das mercadorias, permitindo a produção de bens e o uso de técnicas que dependem intensamente em uma ampla variedade de bens e serviços intermediários especializados (RODRÍGUES-CLARE, 1996, p. 4). Mais que isto, como diz o próprio Smith (1996, p. 65), "o maior aprimoramento das forças produtivas do trabalho, e a maior parte da habilidade, destreza e bom senso com os quais o trabalho é em toda parte dirigido ou executado, parecem ter sido resultados da divisão do trabalho". Nesse sentido, Smith atribui à divisão do trabalho grande parte da melhoria no desempenho das técnicas usadas na produção. Não se pode negligenciar o fato de que a divisão do trabalho, como descrita por Smith, é uma forma de inovação de processo que, por sua vez, ajuda a entender o desenvolvimento do próprio capitalismo. Se essa inovação de processo confere vantagem competitiva às firmas (maior eficiência), então estas tendem a responder melhor ao mercado e, portanto, se consolidarem na indústria, expulsando as ineficientes.

A divisão do trabalho, por sua vez, está relacionada com o termo "progresso técnico", pois amplia a razão produto por trabalhador e, portanto, desloca a função de produção (SOLOW, 1957, p. 312). No entanto a definição dada para este último termo não esgota todo seu significado. 
Desde os aspectos quantitativos, como sua mensuração, quanto os qualitativos, como sua abrangência, o fato é que esse termo é empregado de diferentes formas sob diferentes contextos. Por exemplo, o progresso técnico pode, em alguns casos, ser entendido como progresso tecnológico se o autor tiver em mente não apenas o fato de produzir mais com a mesma quantidade de insumos, mas o fato de alterar substancialmente o processo de produção, a manufatura e a própria maneira como as pessoas se relacionam.

As mudanças do ambiente de trabalho, no interior da firma, oriundas da divisão do trabaIho são postas em prática pelo empresário, que as executa para aumentar a produtividade dos seus empregados e a competitividade da firma. Para dividir as tarefas do trabalho de maneira adequada e aumentar a produtividade dos empregados, os empresários, muitas vezes, precisam contratar novos trabalhadores. Essa contração irá ocorrer sempre que o empresário esperar uma receita de venda, proveniente do trabalho de seus novos operários, maior do que o necessário para Ihe restituir o estoque, o patrimônio ou o capital investido (SMITH, 1996, p. 102). Como o empresário deve sempre avaliar os ganhos e as perdas de suas decisões empresariais, não se pode afirmar que, sempre que forem conhecidas novas técnicas ou novos arranjos organizacionais, eles serão executados. Isso ocorre porque nem sempre os ganhos advindos dessas mudanças superam os seus custos e, portanto, o empresário, em Smith, é entendido como um agente racional o suficiente para ser capaz de considerar custos e benefícios entre as alternativas em um ambiente de incerteza. Nesse sentido, as qualidades do empresário não se restringem à gestão de pessoas e recursos, mas também envolve a capacidade de saber avaliar os riscos, na busca constante pela eficiência e pela inovação.

Em relação ao desenvolvimento do capitalismo, Smith (1996, p. 67) afirma que "as nações mais opulentas geralmente superam todos os seus vizinhos tanto na agricultura como nas manufaturas" e, continua, "suas terras geralmente são mais bem cultivadas, e, pelo fato de investirem mais trabalho e mais dinheiro nelas, produzem mais em proporção à extensão e à fertilidade natural do solo", revelando o fato de que alguns países podem se sobressair sobre outros, dependendo da diferença qualitativa e quantitativa da capacidade de investir e de trabalhar que existe entre eles.

Todas essas diferenças fazem remissão, em última instância, à capacidade de o país realizar uma divisão do trabalho mais extensa e profunda. Mais precisamente, Smith (1996, p. 68) aponta as três causas da superioridade de um país em relação a outro, quais sejam, i) a destreza existente em cada trabalhador - um trabalhador mais habilidoso consegue produzir mais no mesmo tempo que trabalha um menos habilidoso; ii) a poupança do tempo despendido entre alternâncias de tarefas - evitar que se perca tempo mudando de uma tarefa para outra gera um aproveitamento maior do tempo de trabalho; e, iii) a invenção de máquinas que facilitam e encurtam a tarefa do trabalhador. Todos esses tópicos estão conectados com a divisão do trabalho e, em maior ou menor grau, com a capacidade de o país produzir riqueza, afetando, portanto, a própria capacidade de desenvolvimento. Os países que conseguem educar e treinar bem seus trabalhadores satisfazem o primeiro item. Já os países que possuem firmas hábeis o suficiente para organizar o processo produtivo de forma eficiente satisfazem o segundo item. Por fim, os países que investem em pesquisa e desenvolvimento criam condições estruturais e institucionais para que novas ideias se materializem em novas tecnologias e, logo, são capazes de satisfazer o terceiro item. Destarte, boa parte da desigualdade de renda entre os países pode ser explicada, para Smith, a partir das diferenças nos aspectos supracitados. 
Note como cada um dos aspectos elencados por Smith está associado, em maior ou menor nível, com o conceito de inovação. Primeiro, é fácil ver que o refinamento da habilidade do trabalhador não deixa de ser oriundo da inovação no processo de fabricação da mercadoria. Esse aperfeiçoamento da capacidade de trabalho pode ser fruto de uma ideia inteiramente nova ou, até mesmo, do aprendizado a partir de algo já existente (imitação). Em qualquer um dos casos, a inovação, do ponto de vista da firma ou do trabalhador, engendra ganhos de produtividade que ampliam a capacidade de trabalho, favorecendo a produção e a prosperidade econômica.

O segundo item, a saber, o tempo poupado em deixar uma tarefa concluída e começar uma nova, também pode ser entendido como um tipo de inovação. Ora, antes da revolução industrial e do assalariamento da mão de obra, todas as etapas da produção eram executadas individualmente, associadas, na maior parte das vezes, a longos períodos necessários para o treinamento dos artesãos e elevadas remunerações. No entanto, com o processo de divisão do trabalho, repartem-se as tarefas de um mesmo trabalho entre os empregados, substituindo os antigos por trabalhadores não qualificados, dotados de salário inferior e menos eficientes (NATHAN, 1993, p. 25). Como há uma mudança no paradigma de produção, pode-se associar tal advento à inovação de processo. O último item refere-se à criação de máquinas capazes de facilitar e abreviar o trabalho. Não é difícil ver que se trata de uma inovação de processo, uma vez que as máquinas a que Smith se refere poupam trabalho, isto é, altera-se a técnica utilizada para executar o trabalho a fim de se obter um maior rendimento.

Para Smith (1996), a combinação de todos estes três elementos da divisão do trabalho condiciona a quantidade da riqueza de uma nação. A riqueza de uma nação, por sua vez, produz efeitos sobre a trajetória econômica do país e, portanto, altera substancialmente a dinâmica da sociedade. Sendo assim, dada uma nação, em momentos de escassez de divisão do trabalho nos três domínios, reduz-se a riqueza gerada no período e, portanto, reduzem-se o consumo e o investimento. De maneira análoga, pode-se deduzir que, em momentos de abundância de inovação dos aspectos elencados por Smith (1996), aumenta-se a riqueza criada pela nação e, portanto, aumentam-se o consumo e o investimento. Logo, os ciclos econômicos podem ser explicados pelas oscilações dos elementos destacados por Smith (1996, p. 68). Note ainda que o lado da demanda não possui relação com essas mudanças na capacidade de a nação realizar divisão do trabalho e, portanto, trata-se de ciclos econômicos reais, pois suas causas são derivadas, exclusivamente, do lado da oferta, isto é, "because of their emphasis on the role of real shocks, particularly technology shocks, in driving business fluctuations" (REBELO, 2005, p. 218).

Além desses aspectos relacionados às flutuações econômicas, pode-se derivar, desta análise sobre a divisão do trabalho, algumas intuições sobre o processo de concorrência entre as firmas, uma vez que a divisão ocorre, inicialmente, dentro delas. Nesse sentido, antes de se propagar por todo o sistema econômico, os efeitos da divisão do trabalho aparecem, primeiramente, na firma e em seu mercado de atuação. Nesses termos, dado um mercado qualquer, se uma firma realiza a divisão do trabalho, ela reduz o tempo gasto para produzir uma determinada quantidade de produto. Se for uma firma de trabalho puro, pode-se dizer que ela consegue produzir o mesmo de antes, mas com menos horas despendidas para o trabalho ou que consegue produzir um pouco mais do que antes com a mesma quantidade de horas despendidas no trabalho.

Proposição 1: Em qualquer um dos casos, pode-se afirmar que, a produtividade média e marginal aumentaram. A demonstração é a seguinte: fixe um nível $K$ qualquer para o estoque de capital e suponha uma função de produção quase-côncava em $L, f(L)=A L^{\alpha}$. Esta função 
representa a função de produção da firma antes de realizar a divisão do trabalho, $\operatorname{com} A>0$ , $0<\alpha<1$. Agora, seja $g(L)=(A+\delta) L^{\alpha}$ a função de produção da firma após realizar a divisão do trabalho, $\operatorname{com} \delta>0$ representando a poupança do tempo gasto com a alternância entre as tarefas devido à divisão do trabalho. Nesse sentido, quanto maior for a economia de tempo na mudança de uma para outra tarefa, maior o valor que esse parâmetro assume. Assim, por definição, a produtividade média inicial é $\frac{f(L)}{L}=A L^{\alpha-1}$ e a produtividade média final é $\frac{g(L)}{L}=(A+\delta) L^{\alpha-1}$. Note que $\frac{g(L)}{L}=\frac{f(L)}{L}+\delta L^{\alpha-1}$, como $\alpha$ e $\delta$ são parâmetros positivos, tem-se que o termo $\delta L^{\alpha-1}$ é positivo e isto implica $\frac{g(L)}{L}>\frac{f(L)}{L}$, ou seja, a produtividade média final é superior à produtividade média inicial, portanto a divisão do trabalho gerou aumento na produtividade média do trabalho. Em relação à produtividade marginal do trabalho, tem-se que a inicial é $f^{\prime}(L)=\alpha A L^{\alpha-1}$ e a final é $g^{\prime}(L)=\alpha(A+\delta) L^{\alpha-1}$. Pode-se reescrever a produtividade marginal final da seguinte forma $g^{\prime}(L)=\alpha A L^{\alpha-1}+\delta \alpha L^{\alpha-1}=f^{\prime}(L)+\delta \alpha L^{\alpha-1}$. Portanto conclui-se que $g^{\prime}(L)>f^{\prime}(L)$, ou seja, a divisão do trabalho aumenta a produtividade marginal, como se quis demonstrar.

Embora seja possível enumerar diversos exemplos interessantes da divisão do trabalho no contexto da firma, o mais notável deles foi proporcionado por Adam Smith em "A Riqueza das Nações". Nesse livro, o autor, com a genialidade que lhe é peculiar, expõe de maneira muito clara a aplicação da divisão do trabalho no contexto de uma firma que fabrica alfinetes. Basicamente, de acordo com Smith (1996, p. 65), um trabalhador não qualificado para essa tarefa, nem acostumado com a utilização das máquinas disponíveis na empresa, raramente conseguiria produzir um único alfinete em um dia de trabalho. Mas, por outro lado, a firma consegue obter grande aprimoramento de eficiência se executa a divisão do trabalho na produção de alfinetes, isto é, organiza a produção de forma que

[...] um operário desenrola o arame, um outro o endireita, um terceiro o corta, um quarto faz as pontas, um quinto o afia nas pontas para a colocação da cabeça do alfinete; para fazer uma cabeça de alfinete requerem-se 3 ou 4 operações diferentes; montar a cabeça já é uma atividade diferente, e alvejar os alfinetes é outra; a própria embalagem dos alfinetes também constitui uma atividade independente. Assim, a importante atividade de fabricar um alfinete está dividida em aproximadamente 18 operações distintas, as quais, em algumas manufaturas são executadas por pessoas diferentes, ao passo que, em outras, o mesmo operário às vezes executa 2 ou 3 delas. (SMITH, 1996, p. 66).

Assim como o caso da fábrica de alfinetes, numerosas firmas encontram, na divisão do trabalho, o caminho pelo qual podem aumentar a produtividade dos funcionários e, então, escolhem dividir em partes maiores as etapas da produção dos bens e serviços que oferecem ao mercado. Nessa esteira, Smith (1996, p. 66) arremata,

Em qualquer outro ofício e manufatura, os efeitos da divisão do trabalho são semelhantes aos que se verificam nessa fábrica insignificante embora em muitas delas o trabalho não possa ser tão subdividido, nem reduzido a uma simplicidade tão grande de operações. A divisão do trabalho, na medida em que pode ser introduzida, gera, em cada ofício, um aumento proporcional das forças produtivas do trabalho.

Contudo, nem sempre, realizar esta mudança é fácil dentro da empresa, pois existem barreiras de diversas naturezas que a impõe restrições. Segundo a FINEP (1997, p. 129), são exemplos de barreiras externas à inovação: i) carência de financiamento; ii) ausência de demanda 
por novos produtos aos preços considerados necessários para que suas inovações sejam economicamente viáveis; iii) ausência de trabalhador qualificado disponível ao salário considerado adequado para que as inovações sejam economicamente viáveis; iv) ausência de infraestrutura; v) falta de conhecimento sobre tecnologia ou mercados; vi) legislação complexa ou onerosa e fragilidade dos direitos de propriedade. Em relação às barreiras internas à empresa, os exemplos são diversos, e cada firma pode ter sua peculiaridade. Entre esses, pode-se citar: i) estrutura gerencial da empresa rígida; ii) atitude negativa do pessoal com relação a mudanças; iii) inércia da rotina empresarial, que muitas vezes enrijece as tarefas de cada funcionário; iv) escassez da sinergia organizacional; v) clima organizacional desfavorável; vi) restrições de gerência e liderança, vii) falhas de comunicação e de planejamento etc. Todas essas barreiras podem comprometer a adequada divisão das tarefas e, portanto, reduzir os ganhos de produtividade do trabalho e a capacidade de inovação empresarial.

Como a divisão do trabalho implica maior eficiência para a firma inovadora, uma vez realizada, o posicionamento estratégico da empresa no mercado não será mais, necessariamente, o mesmo. Dependendo da estrutura do mercado, a firma pode alterar sua política de preços e quantidades ofertadas, provocando reações nas firmas concorrentes e, portanto, é capaz de afetar o nível de bem-estar da sociedade. Na prática, significa dizer que se o empresário percebeu que há um benefício líquido em realizar a divisão do trabalho, ele irá realizá-la. Tão logo esteja completa essa transformação no interior da firma, o empresário reduz o custo total médio dos bens e serviços que produz. Essa redução do custo total médio abre espaços para uma nova avaliação do ambiente de negócios em que a firma se encontra e, consequentemente, uma revisão das decisões que estavam sendo tomadas. Assim, dependendo do nível de competição do mercado, a firma pode agora escolher uma estratégia que, antes da inovação, não era factível. Por exemplo, pode se tornar factível para a firma reduzir os preços de seus produtos no curto prazo, sem necessariamente incorrer em prejuízos, para expulsar os concorrentes. Além disso, pode-se tornar factível manter o preço inalterado para aproveitar a redução no custo total médio e realizar uma elevação no lucro no curto prazo, seja para recompor o caixa, para pagar dividendos ou mesmo para realização de novos investimentos.

\section{SCHUMPETER E O EMPREENDEDORISMO: UM NOVO PATAMAR É CONFERIDO À INOVAÇÃO}

A partir dos escritos canônicos de Smith, a Economia passou a ser reconhecida como ciência determinada, separada do Direito e da Moral, o que permitiu grandes avanços na teoria econômica. No entanto, ainda que o progresso da teoria econômica tenha sido sem precedentes, principalmente no arcabouço neoclássico, ela ainda continha diversos limites que dificultavam a absorção de muitos conceitos que eram importantes para a compreensão do funcionamento do sistema capitalista. Nessa esteira, no livro "O Fenômeno Fundamental do Desenvolvimento Econômico", Schumpeter aponta os limites da teoria econômica daquele período, destacando especialmente, sua incapacidade para incorporar o papel do empreendedor e da inovação no processo de acumulação de capital de economias capitalistas, bem como para analisar o fenômeno descontínuo que é o desenvolvimento econômico. Assim, o autor sintetiza sua insatisfação com as análises estáticas e de equilíbrio, por não levarem em consideração estes aspectos dinâmicos do desenvolvimento, da seguinte forma: 
O desenvolvimento, no sentido em que o tomamos, é um fenômeno distinto, inteiramente estranho ao que pode ser observado no fluxo circular ou na tendência para o equilibro. É uma mudança espontânea e descontínua nos canais o fluxo, perturbação do equilíbrio que altera e desloca para sempre o estado de equilíbrio previamente existente. Nossa teoria do desenvolvimento não é nada mais do que um modo de tratar este fenômeno e os processos a ele inerentes. (SCHUMPETER, 1985, p. 47 apud MARTES, 2010, p. 255).

Schumpeter destaca o conceito de "inovação", assim como o de "empreendedor", para explicar o funcionamento da dinâmica capitalista. Para ele, o empreendedor, ao inovar, deve agir ativamente sobre os consumidores se for o caso, o que significa estímulo ao consumo do novo através de propagandas e promoções. Nesses termos, o resultado da inovação é, de certa forma para Schumpeter, mérito dos empresários, depositando sobre eles o sucesso ou o fracasso das próprias decisões:

É, contudo, o produtor que, via de regra, inicia a mudança econômica, e os consumidores, se necessário, são por ele 'educados'; eles são, por assim dizer, ensinados a desejar novas coisas, ou coisas que diferem de alguma forma daquelas que têm o hábito de consumir. (SCHUMPETER, 1982, p. 9).

De acordo com Schumpeter (1961, p. 109), o sistema capitalista é um processo evolutivo, isto é, um sistema cuja dinâmica é baseada na capacidade contínua de os indivíduos se adaptarem ao ambiente econômico. Nesse sentido, é fundamental encontrar a força motriz do sistema, não se iludindo com fatores que apenas superficialmente modificam suas estruturas. Assim, como atesta o autor (SCHUMPETER, 1961, p. 110),

[...] não se deve esse caráter evolutivo do processo capitalista apenas ao fato de que a vida econômica transcorre em um meio natural e social que se modifica e que, em virtude dessa mesma transformação, altera a situação econômica. [...] Tampouco esse caráter evolutivo se deve a um aumento quase automático da população e do capital, nem às variações do sistema monetário, do qual se pode dizer exatamente o mesmo que se aplica ao processo capitalista. O impulso fundamental que põe e mantém em funcionamento a máquina capitalista procede dos novos bens de consumo, dos novos métodos de produção ou transporte, dos novos mercados e das novas formas de organização industrial criadas pela empresa capitalista.

Sendo assim, é importante destacar esse caráter adaptativo do sistema capitalista, que premia os indivíduos mais hábeis em reagir aos desafios do ambiente competitivo. Vislumbra-se a realização da concorrência, como mencionado acima, por meio da criação de novos paradigmas econômicos, isto é, na criação de novas formas de interação econômica entre os indivíduos. Nesses termos, a criação desses novos paradigmas engendra a destruição dos antigos, fazendo com que os primeiros ocupem o lugar dos últimos.

Nas palavras do próprio Schumpeter (1961, p. 110), esse "processo de mutação industrial que revoluciona incessantemente a estrutura econômica a partir de dentro, destruindo incessantemente o antigo e criando elementos novos" é chamado de destruição criadora. Essa destruição criadora é executada através do empreendedor schumpeteriano, compreendido nesta teoria como "aquele que realiza novas combinações dos meios produtivos, capazes de propiciar desenvolvimento econômico" (SCHUMPETER, 1985, p. 49 apud MARTES, 2010, p. 261).

Uma vez implementada a inovação e auferido o lucro extra pelo empreendedor, os demais empresários passam, então, a compreender melhor o novo cenário e traçam alternativas de reação ao estímulo inicial. Assim, novos estabelecimentos começam a aparecer na tentativa de oferecer algo similar ao que foi inovado e, com isto, apropriarem-se de partes do lucro extra. 
Logo, contratam-se mais trabalhadores, produz-se em maior quantidade, tendo um lucro relativamente estável. Nesse momento, há uma expansão do emprego e da renda, com possível aumento do salário real e do bem-estar social. Posteriormente, reduz-se parcialmente o preço prêmio do novo produto e dilui-se o lucro da inovação entre as firmas instaladas na indústria. Assim, com a mudança dos sinais do mercado e com a queda do lucro que cada firma apropria, alteram-se os custos de oportunidade relativos em estar nesta indústria ou em outra. Nesse período, "ocorre uma reorganização completa da indústria, com aumento de produção, luta concorrencial, superação dos estabelecimentos obsoletos, possível demissão de trabalhadores etc." (SCHUMPETER, 1982, p. 132), diluindo o lucro extra na indústria, reduzindo o incentivo à entrada de novas firmas e aumento ao incentivo à saída de algumas já estabelecidas.

Para Schumpeter (1961, p. 110), a pedra angular do capitalismo reside nesse conceito, e a ele todas as empresas capitalistas devem se adaptar se quiserem sobreviver. Dessa constatação, decorrem duas importantes considerações. A primeira delas diz respeito ao tempo necessário para a percepção integral dessas mutações por todo o sistema capitalista. Para o autor, os efeitos da destruição criadora são sentidos por longos períodos, décadas ou até mesmo séculos. Assim, para compreender o capitalismo não se pode fazer um pequeno recorte temporal para análise, pois pequenos espaços de tempo são insuficientes para revelarem toda a potência e toda a penetrabilidade de diversas inovações ao longo do sistema econômico.

Logo, quando, em 1983, a Motorola lançou o primeiro aparelho celular do mundo, o Motorola DynaTAC 8000X, ainda que soubesse que esta inovação pudesse alterar os paradigmas econômicos da humanidade, jamais imaginaria a magnitude dessa mudança. Nesse sentido, seria impossível pensar que, em 30 anos, a partir desse aparelho inicial, os dispositivos tivessem avançado tanto que fosse possível realizar ligações em tempo real a custo negligenciável, requisitar e monitorar companhias de transporte de pessoas, estar conectado por redes sociais a qualquer pessoa no mundo etc. Nessa esteira, diversas outras invenções seguiram este mesmo caminho: começaram provocando pequenas mudanças no início e, ao longo do tempo, à medida que estavam sendo absorvidas pelo sistema econômico, passaram a desencadear diversas outras modificações que, à princípio, seriam impossíveis de se prever. A maioria dessas invenções foram realizadas após a revolução industrial no séc. XIX, principalmente o motor à combustão, o telefone, a lâmpada, o avião, a penicilina, entre outros.

A outra constatação, igualmente importante, refere-se ao fato de que o que ocorre a uma parte isolada do capitalismo apenas detalha o funcionamento de mecanismos do próprio capitalismo, mas estes não agregam nada nas conclusões de ordem geral. Isto significa que só se pode sentenciar a respeito do capitalismo como um todo, relacionando-se as partes com o corpo orgânico do capitalismo, isto é, compreender a relação existente entre as partes e o todo. Sobre essa segunda constatação, Schumpeter (1961, p. 111) esclarece:

Todos os exemplos de estratégia econômica adquirem a sua verdadeira significação apenas em relação a esse processo e dentro da situação por ele criada. Necessitam ser observados no papel que desempenham na tempestade eterna da destruição criadora, pois não podem ser compreendidos independentes deste processo ou baseados na hipótese de que há uma calmaria perene.

A partir destas considerações, fica claro como é falho o entendimento a-histórico do capitalismo, que despreza sua própria trajetória passada, assim como sua natureza orgânica. Logo, restringir as ferramentas de compreensão do funcionamento do capitalismo ao ferramental 
matemático de maximização de utilidade, para os indivíduos, e maximização de lucro, para as firmas, bem como delimitar de maneira rígida a dimensão temporal de análise, significa incorrer em omissões e graves erros no entendimento do capitalismo. Isto, no entanto, não se traduz na necessidade de abandono de tais ferramentas, mas somente de que estas devem ser utilizadas com moderação e jamais desconectadas de um contexto histórico, bem como da noção orgânica do sistema capitalista.

A mutação industrial opera através da figura do empreendedor que, para Blaug (1995, p. 464), "is the source of all dynamic change in an economy and the capitalist system; for Schumpeter cannot be understood except in terms of the conditions giving rise to entrepreneurship". Neste sentido, é crucial, também, o entendimento do que é empreender em seu sentido mais completo. Assim, pode-se conceituá-lo da seguinte forma:

Empreender é inovar a ponto de criar condições para uma radical transformação de um determinado setor, ramo de atividade, território, onde o empreendedor atua: novo ciclo de crescimento, capaz de promover uma ruptura no fluxo econômico continuo, tal como descrito pela teoria econômica neoclássica. A inovação não pode ocorrer sem provocar mudanças nos canais de rotina econômica. (SCHUMPETER, 1985, p. 49 apud MARTES, 2010, p. 261).

Os exemplos de inovações de sucesso se abundam. Entre as inovações que mudaram o mundo e a maneira como as pessoas interagem, pode-se citar o aplicativo de mensagens Whatsapp, a rede social Facebook, o buscador da Google, o repositório de vídeos YouTube, o aplicativo de transporte de pessoas Uber, o sistema de streaming de séries e filmes Netflix, os serviços de armazenamento na nuvem Dropbox e o SpaceX do Elon Musk. Todas essas empresas têm, pelo menos, uma coisa em comum: todos os idealizadores tomaram o risco de empreender. Algumas delas usaram inovações incrementais existentes para propor inovações em saltos, disruptivas, capazes de mudar o paradigma social vigente e conduzir a sociedade para um nível superior de bem-estar, integração e desenvolvimento.

Posto isto, é fundamental entender o background do empresário empreendedor, isto é, conhecer quais são as causas do empreender empresarial - as variáveis que afetam a capacidade e a motivação de empreender. Nessa esteira, Schumpeter enfatiza o fato de que o empreendedor pode ser uma pessoa muito discreta, que não precisa convencer os outros do mercado sobre a "desejabilidade" de sua visão, capacidades ou habilidades, porque ele é capaz de conduzir os meios de produção em novos canais e, muitas vezes, o único homem que ele tem para convencer ou para impressionar é o banqueiro capaz de financiá-lo (CROITORU, 2012, p. 143).

Buscando compreender o que há de mais profundo no comportamento empresarial dos indivíduos, Schumpeter (1982, p. 98-9) destacou algumas qualidades psicológicas dos empreendedores, quais sejam,

Antes de tudo, há o sonho e o desejo de fundar um reino privado, e comumente, embora não necessariamente, também uma dinastia. Há então o desejo de conquistar: o impulso para lutar, para provar-se superior aos outros, de ter sucesso em nome não de seus frutos, mas do próprio sucesso. Finalmente, há a alegria de criar, de fazer as coisas, ou simplesmente de exercitar a energia e a engenhosidade.

Nesses termos, a beleza da complexidade psicológica da mente empreendedora não reside somente no ímpeto desmedido em obter o sucesso e realizar as coisas que precisam ser feitas para alcançar esse fim, aceitando diversos níveis e tipos de incerteza para que possa ver sua criação tomando vida e forma no mundo real. Além disso, reside também na semelhança de 
se entender o combate no campo econômico com o combate no campo do esporte. Assim, há uma similitude na vontade de vencer pela vitória em si e não sobre os frutos da própria vitória, uma vontade de se provar superior não necessariamente para comandar, mas para satisfazer essa necessidade de ser grande. Do ponto de vista econômico, essas diversas condições podem ser simplificadas, bastando entender que o empreendedor executará a inovação quando formar expectativas de que a partir dela poderá obter um excedente das receitas totais sobre os custos totais (SCHUMPETER, 1982, p. 131).

Assim como as teorias pregressas sobre empreendedorismo, para Schumpeter o empreendedor assume um papel funcional que não é necessariamente corporificado numa única pessoa física e, certamente, nem em um grupo de indivíduos bem definido. O empreendedor schumpeteriano pode ser o capitalista ou mesmo um gerente corporativo, mas se todas essas funções diferentes estarão combinadas em uma ou mais pessoas dependerá da natureza dos mercados de capitais e das formas de organização industrial. Nesse sentido, a quantidade real de empreendedores em uma economia capitalista está mudando constantemente, pois sua função é de difícil separação de outros tipos de atividades econômicas (BLAUG, 1995, p. 464).

Note que indivíduos assim não são encontrados facilmente na sociedade, ainda que sejam fundamentais para o desenvolvimento econômico, tanto pela capacidade de implementar construções abstratas no mundo real quanto pela criatividade e engenhosidade de observar oportunidades de negócios. Para Schumpeter (1982, p. 99), "essas e outras peculiaridades inerentes ao mecanismo da sociedade 'aquisitiva' tornam muito difícil substituí-lo como motor do desenvolvimento industrial". Posto isto, ainda que o autor se esquive de fornecer uma resposta de como multiplicar o número de indivíduos empreendedores numa sociedade, fica claro o quanto é desejável que existam condições institucionais e sociais para que seja factível o desenvolvimento das habilidades que transformem os indivíduos em empreendedores (SCHUMPETER, 1982, p. 99).

Portanto, para Schumpeter, a figura do empreendedor, com todas as suas nuances psicológicas e todos seus elementos subjetivos, é crucial para se entender o comportamento das empresas, a capacidade de inovação, assim como o desenvolvimento do próprio sistema capitalista. Isso acontece porque é, através de personalidade do indivíduo empreendedor, da sua assunção de riscos e de suas ações inovadoras, na busca incessante de lucro econômico positivo e de obter sucesso, que o processo de desenvolvimento do sistema capitalista se realiza. Esse progresso é antecipado por flutuações econômicas e desequilíbrios friccionais que, mais cedo ou mais tarde, são assimilados pelo próprio sistema, levando-o a um novo patamar qualitativo de equilíbrio econômico e bem-estar social.

\section{OS PAPÉIS DA INOVAÇÃO E DO EMPREENDEDOR NA ECONOMIA BRASILEIRA: COMO ESSES ELEMENTOS PODEM AJUDAR A ENTENDER A ECONOMIA BRASILEIRA}

Os papéis da inovação e do empreender na economia brasileira são os mesmos para qualquer economia capitalista e, portanto, são fundamentais para compreender a situação da economia brasileira atualmente. Nesse sentido, compreender em que medida estão surgindo empreendedores e com qual ritmo estão se dando as inovações é crucial em qualquer análise econômica da economia brasileira contemporânea.

Como exposto previamente, para que a figura do empreendedor apareça, é necessário, entre outras coisas, que existam oportunidades de negócio. No entanto as oportunidades de 
negócios não são suficientes, uma vez que elas podem ser economicamente inviáveis. Nesse sentido, ainda que existam indivíduos potencialmente empreendedores na economia brasileira, enfrentar uma estrutura de alto custo de capital torna, muitas vezes, inviável a execução dos projetos. Essa inviabilidade ocorre por vários canais, entre eles, pelo alto valor da taxa de juros do setor bancário, bem como pela concorrência com outros ativos livres de risco que pagam uma alta taxa de retorno, como os títulos públicos federais comercializados pelo Tesouro Nacional.

Existem diversos elementos que ajudam a explicar o porquê do custo de capital no Brasil ser tão elevado. Entre esses elementos estão o spread bancário, a taxa de juros de curto prazo, a volatilidade cambial, indexação dos contratos dos preços administrados, a carência da infraestrutura logística e a qualidade da segurança jurídica na celebração dos contratos (NEVES et al., 2007). Para mais detalhes sobre o custo de capital no Brasil ver Afanasieff, Lhacer e Nakane (2002), Belaisch (2003), Nakane (2003), Holland (2006) e Silva, Oreiro e Paula (2006).

Nesse sentido, além do elevado custo de capital, a concorrência que o título público livre de risco oferece ao projeto do empreendedor é, deveras, significante em desincentivá-lo. Isso ocorre com frequência porque, não raras as vezes, alocar seus recursos financeiros em títulos livres de risco que pagam, em média, 13\% a.a. são mais atraentes do que arriscar alocar os recursos em projetos que podem render taxas não muito superiores ao que pagam os títulos públicos federais. Desse modo, essa concorrência aliada ao alto custo de capital matam o espírito empreendedor no Brasil e, portanto, impedem que a destruição criativa imponha vigor ao ritmo de crescimento econômico na economia brasileira.

Por outro lado, as condições acima levantadas (baixo custo de capital e baixa concorrência de ativos livres de risco) não são suficientes para o surgimento da figura do empreendedor e, portanto, da inovação. Assim, ainda que existam tais condições propícias para a ação dos empreendedores, existem outros requisitos igualmente necessários. Primeiro, é necessário que existam indivíduos com o espírito de empreendedor, isto é, capazes de perceber as oportunidades de negócios e corajosos para enfrentar os riscos envolvidos nesse processo. E, nesse sentido, é fundamental que existam condições propícias para que esse espírito possa emergir, dentro dos indivíduos, de forma acentuada e generalizada. Em suma, precisa-se que vivam dentro de uma cultura organizada, entre outras coisas, para despertar e impulsionar o espírito empreendedor dos indivíduos (ROESE; BINOTTO; BÜLLAU, 2005). Para que uma cultura exista com essas qualidades, são necessárias diversas ações intencionais para sua criação, pois, dificilmente, algo tão refinado surgirá espontaneamente, principalmente nos casos de localidades com condições institucionais retrógradas ao empreendimento e à inovação.

Nessa esteira, entende-se que o sistema educacional, o núcleo familiar e de convívio social devem ser pautados, também, por aspectos que estimulem as características empreendedoras na formação das crianças, sem prejuízo dos demais valores e aspectos da infância. Destarte, reconhece-se que mecanismos capazes de ativar a criatividade, a liderança, o respeito aos direitos individuais e às regras sociais, à inventividade, à engenhosidade são essenciais tanto para a formação da criança quanto para a consolidação de uma cultura favorável à inovação e, portanto, à prosperidade econômica e social.

Nesse sentido, segundo o autor Aidair (2007), os cursos e as literaturas tradicionais da área de Administração e Negócios enfatizam a formação de executivos que, via de regra, atuarão em grandes corporações multinacionais e nelas farão carreiras. No entanto, ainda hoje, muito pouco se pensa no empreendedorismo como carreira de negócios. Para o autor, essa realidade vem 
sendo alterada no decorrer dos anos; uma vez que, com o fim do modelo de longas carreiras nas organizações e terceirização em larga escala, a valorização de pequenos negócios tem expressivamente aumentado a demanda sobre o tema empreendedorismo. Nesse sentido, atualmente os cursos têm passado a incluir nas grades curriculares esse tema e isso até em nível de graduação, especialização e educação executiva. Assim, essa alteração no ambiente educacional pode desmistificar a percepção que os estudantes têm em relação ao empresário empreendedor, ao mesmo tempo em que estimula práticas empreendedoras e, portanto, o desenvolvimento das habilidades geradoras de indivíduos empreendedores.

Nesta linha, como no Brasil não existe uma cultura favorável ao surgimento de indivíduos empreendedores, bem como existem ativos livres de risco com retornos esperados que concorrem com projetos de investimento produtivo, não há espaço para a inovação. Portanto, de uma ou outra forma, os espíritos empreendedores são sufocados ainda antes de emergirem concretamente através de uma ação inovadora no Brasil. Assim, essa castração do espírito empreendedor implica numa redução da velocidade de criação de novos produtos ou serviços e de novos processos de produção. Ora, se não se realiza investimentos, que são os elementos capazes de ampliar a capacidade produtiva por definição, não há como esperar que o país produzir mais e, com isso, realize o crescimento econômico. Tendo em vista isso, a situação recente da economia brasileira (recessão econômica) escancara esse problema estrutural e cultural que está sendo vivido. Nesse aspecto, para retomar o crescimento econômico, é necessário que se conheça melhor o que significa "empreendedor" e "inovação", bem como suas consequências sobre o capitalismo para que se tome consciência da importância de criar condições para que esses conceitos se manifestem na vontade dos indivíduos, tanto em termos locais, como municípios, quanto em termos nacionais, como países. Logo, medidas emergenciais de caráter estimulante ao espírito empreendedor são fundamentais para o desenvolvimento individual e econômico de países emergentes, como o Brasil.

\section{CONCLUSÃO}

O objetivo deste trabalho foi apresentar uma revisão da literatura sumária sobre a evolução dos conceitos de inovação e de empresário, bem como destacar a importância deles para as firmas e para o próprio funcionamento do sistema econômico. Nesse sentido, passou-se pelos conceitos de divisão do trabalho e firma em Adam Smith, pelos conceitos de empreendedor e de destruição criadora em Schumpeter.

Algumas são as limitações da análise desse trabalho. Entre outros aspectos, não se analisaram os efeitos dinâmicos da inovação sobre o nível de emprego e de salário. Para os fins que o artigo se propôs a atingir, não foi necessário, inicialmente, fazer uma distinção precisa entre inovação radical e inovação incremental. Além disso, não se explicitaram seus efeitos sobre as estruturas de mercado, isto é, de que modo a inovação influencia a concentração ou a desconcentração dos mercados. Para além, dada as questões deixadas em aberto, reside uma lacuna passível de ser preenchida com pesquisas futuras, dando continuidade ao presente artigo.

Pode-se constatar que a divisão de trabalho apresentada por Adam Smith corresponde, de maneira germinal, ao conceito de inovação de Schumpeter, haja vista que o primeiro leva a desequilíbrios temporários no sistema capitalista, lucros econômicos positivos e, portanto, permite compreender a concorrência empresarial de um posto de vista não preço. Além disto, 
mostrou-se como o conceito de inovação e a figura do empreendedor estão mais amadurecidos nos trabalhos de Schumpeter, uma vez que esse autor desenvolve e amplia os embriões conceituais desse escopo, deixados por Smith. Além disso, argumentou-se que a inovação e o empreendedor não são apenas importantes do ponto de vista da empresa, mas vitais para o próprio funcionamento do capitalismo. Por fim, mostrou-se como é importante a construção de políticas públicas voltadas para a cultura da inovação no Brasil a fim de que seja possível enfrentar a recessão econômica atual de maneira permanente, construindo bases sólidas para cultivar o espírito empreendedor a se manifestar nas ações dos indivíduos, propiciando espaço privilegiado para a inventividade e a inovação.

\section{REFERÊNCIAS}

AFANASIEFF, T. S.;, LHACER, P. M.; NAKANE, M. I. The determinants of bank interest spread in Brazil. Money Affairs, v. XV, n. 2, p.183-207, 2002.

AIDAIR, M. M. Empreendedorismo. 1. ed. São Paulo: Thomson, 2007.

BELAISCH, A. Do Brazilian banks compete? IMF Working Paper WP/03/113, 2003.

BLAUG, M. Economic theory in retrospect. 4. ed. Cambridge: Cambridge University Press, 1995.

CROITORU, A. Schumpeter, J.A., 1934 (2008), The Theory of Economic Development: an inquiry into profits, capital, credit, interest and the business cycle, translated from the German by Redvers Opie, New Brunswick (U.S.A) and London (U.K.): transaction publishers: a review to a book that is 100 years old. Journal of Comparative Research in Anthropology and Sociology, v. 3, n. 2, 2012.

FINEP. Manual de Oslo: proposta de diretrizes para coleta e interpretação de dados sobre inovação tecnológica. Brasília, 1997.

HEERTJE, A. Schumpeter, Joseph Alois (1883-1950). In: DURLAUF, Steven N.; BLUME, Lawrence E. (Ed.). The New Palgrave Dictionary of Economics. 2. ed. Basingstoke, Reino Unido: Palgrave Macmillan, 2008.

HISRICH, R. D.; PETERS, M. P. Empreendedorismo. 5. ed. Porto Alegre: Bookman, 2004.

HOLLAND, M. Por que as taxas de juros reais são tão elevadas no Brasil. Boletim Economia \& Tecnologia, v. 4, n. 2, p. 27-42, 2006.

INNOVATION. Dictionary.com Unabridged. [s.d.]. Random House, Inc. Disponível em: <http://www. dictionary.com/browse/innovation>. Acesso em: 10 maio 2017.

MANKIW, N. G. Principles of economics. 7. ed. Boston, EUA: Cengage Learning, 2015.

MARTES, A. C. B. Weber e Schumpeter: a ação econômica do empreendedor. Revista de Economia Política, v. 30, n. 2 (118), p. 254-70, abr./jun. 2010.

MCCRAW, T. K. O Profeta da Inovação: Joseph Schumpeter e a Destruição Criativa. Rio de Janeiro: Record, 2012.

NAKANE, M. I. Concorrência e spread bancário: uma revisão da evidência para o Brasil. In: BANCO CENTRAL DO BRASIL. Juros e spread bancário no Brasil: avaliação de 4 anos do projeto. Brasília: Banco Central do Brasil, 2003. p. 58-67.

NATHAN, R. Exploring the black box: technology, economics and history. Cambridge: Cambridge University Press, 1993. p. 27-38.

NEVES, A. L.; PAULA, L. F. R.; SILVA, G. J. C.; OREIRO, J. L. C.; AMARAL, R. Q. Por que o custo de capital no Brasil é tão alto? Texto para Discussão - Anpec, 2007.

PEÑALOZA, R. Reflexões sobre o lucro segundo Schumpeter, Clark, Knight e Kirzner. 2016. Disponível em: <https://medium.com/@milesmithrae/reflex\%C3\%B5es-sobre-o-lucro-segundo-schumpeter-clark-knighte-kirzner-rodrigo-pe\%C3\%B1aloza-24-iv-2016-a74ef72b9d49\#.a0x7kjgrl>002E

INTERAÇÕES, Campo Grande, MS, v. 19, n. 1, p. 155-170, jan./mar. 2018 
REBELO, S. Real business cycle models: past, present and future. Scandinavian Journal of Economics, v. 107, n. 2, p. 217-38, 2005.

RODRÍGUEZ-CLARE, A. The division of labor and economic development. Journal of Development Economics, v. 49, n. 1, p. 3-32, abr. 1996.

ROESE, A.; BINOTTO, E.; BÜLLAU, H. Empreendedorismo e a cultura empreendedora: um estudo de caso no Rio Grande do Sul. II Seminário de Gestão de Negócios. FAE Centro Universitário. Blumenau, 2005. Disponível em: <http://www.ceap.br/material/MAT28042012162613.pdf>. Acesso em: ago. 2017.

SCHUMPETER, J. A. A Teoria do Desenvolvimento Econômico: uma investigação sobre lucro, capital, crédito, juro e o ciclo econômico. Rio de Janeiro: Nova Cultural, 1982.

SCHUMPETER, J. A. Capitalism, socialism and democracy. New York: Harper and Brothers, 1961.

SILVA, G. J. C.; OREIRO, J. L.; PAULA, L. F. R. Comportamento do spread bancário no Brasil: uma avaliação empírica recente. 2006. (mineo.).

ŚLEDZIK, K. Schumpeter's view on innovation and entrepreneurship. In: HITTMAR, Stefan (Ed.). Management Trends in Theory and Practice. Zilina, Eslováquia: Faculty of Management Science and Informatics, University of Zilina; Institute of Management by University of Zilina, 2013.

SMITH, A. A riqueza das nações. Rio de Janeiro: Nova Cultural, 1996. v. I.

SOLOW, R. M. Technical change and the aggregate production function. The Review of Economics and Statistics, v. 39, n. 3, p. 312-20, 1957.

\section{Sobre os autores:}

Matheus Silva de Paiva: Doutorando em Economia pela Universidade de Brasília (UnB). E-mail: matheus.paiva@ucb.br

George Henrique de Moura Cunha: Doutor em Economia pela Universidade de Brasília (UnB). Mestre em Economia pela Universidade Federal de Pernambuco (UFPE). E-mail: georgehmc@outlook.com

Celso Vila Nova Souza Junior: Doutor em Economia pela Universidade de Brasília (UnB). E-mail: celsov@ucb.br

Michel Constantino: Doutor em Economia pela Universidade de Católica de Brasília (UCB). E-mail: michel@ucdb.br 